\title{
Identification and Visualization of the Conceptual Structure and Main Research Themes of Studies in Informatics and Control Journal from 2008 to 2019
}

\author{
María GUTIÉRREZ-SALCEDO ${ }^{1}$, José Ricardo LÓPEZ-ROBLES ${ }^{2 *}$, María Ángeles MARTÍNEZ- \\ SÁNCHEZ ${ }^{3}$, Enrique HERRERA-VIEDMA ${ }^{4}$, Manuel Jesús COBO ${ }^{5}$ \\ ${ }^{1}$ Department of Management, Marketing and Sociology, University of Jaen, Campus Las Lagunillas, s/n, \\ Jaén, 23071, Spain \\ msalcedo@ujaen.es \\ ${ }^{2}$ Postgraduate Program of Engineering and Applied Technology (National Laboratory CONACYT-SEDEAM), \\ Autonomous University of Zacatecas, Av. Ramón López Velarde Col. Centro, Zacatecas, 98000, Mexico \\ ricardolopezrobles@outlook.com (*Corresponding author) \\ ${ }^{3}$ Department of Social Work, University of Granada, Avenida del Hospicio, s/n, Granada, 18010, Spain \\ mundodesilencio@ugr.es \\ ${ }^{4}$ Department of Computer Science and Artificial Intelligence, University of Granada, Avenida del Hospicio, \\ s/n, Granada, 18010, Spain \\ viedma@decsai.ugr.es \\ ${ }^{5}$ Department of Computer Science and Engineering, University of Cádiz, Avenida de la Universidad no. 10, \\ Puerto Real, 11519, Spain \\ manueljesus.cobo@uca.es
}

\begin{abstract}
Studies in Informatics and Control journal is a quarterly publication for all those involved in the field of Information Technology (IT). Studies in Informatics and Control journal provides important perspectives on topics relevant to IT, with an emphasis on useful applications in the most important areas of IT, and it is aimed at advanced practitioners and researchers in the field of IT. The core subjects covered by Studies in Informatics and Control journal are relating to innovative research and practice in Information Technology: IT use in control and management systems; integration of IT with control; application of IT in socio-economic systems and manufacturing processes, mainly. The current research conducts a bibliometric performance and conceptual structure analysis of Studies in Informatics and Control journal from 2008 to 2019. Firstly, the journal performance is analysed according to the data retrieved from the Web of Science Core Collection, putting the focus on the productivity of the authors, citations, countries, organizations and most relevant publications. Finally, the conceptual structure of the journal is analysed with bibliometric software tool SciMAT, identifying the main thematic areas that have been the object of research, their composition, relationship and evolution during the period analysed.
\end{abstract}

Keywords: Studies in Informatics and Control Journal, Bibliometric analysis, Strategic Intelligence, SciMAT, Science Mapping, Journal Performance, Thematic analysis.

\section{Introduction}

Nowadays, the academic and scientific journals constitute one of the main sources of dissemination and communication to expose the results of studies, researches and projects, which results in both the visibility of the organizations and the authors and, for this reason, it has become a key tool to evaluate these organizations and researchers in respect of their knowledge field. Therefore, journals are a priority object of study in bibliometric research (Kiesslich et al., 2016; Petersen et al., 2017).

In research whose object of study is the academic or scientific journals, three main different approaches can be pointed out: (1) Techniques and methodologies for bibliometric analysis (Glänzel, 1996; Gutiérrez-Salcedo et al., 2018; Schneider, 2005), (2) Bibliometric performance analysis of authorship and production (Gaviria-
Marin et al., 2019; López-Robles et al., 2019d; Murgado-Armenteros et al., 2015), and (3) Bibliometric thematic analysis (Garcia-Garcia \& Rodriguez-Salvador, 2018; López-Robles et al., 2019c; Stek \& van Geenhuizen, 2016). Additionally, two secondary methods can be added: (a) research focused on the in-depth analysis of a single journal (Li et al., 2019; López-Robles et al., 2019a; López-Robles et al., 2019b; López-Robles et al., 2018; Wang et al., 2019), and (b) research that analyzes several journals or a significant group of them within a discipline or knowledge field (Gorraiz \& Schloegl, 2008; Moral-Muñoz et al., 2019).

In this way, this research conducts a bibliometric analysis of authorship and production and thematic analysis, with the particularity that it covers the background of the journal in one 
whole period. Consequently, the main aim of this paper is to evaluate the Studies in Informatics and Control (SIC) journal evolution from 2008 to 2019 by conducting a bibliometric analysis of authorship and production, emphasizing the identification of the core research themes, their relationship and components by means of a science mapping analysis (Börner et al., 2015) using SciMAT (Cobo et al., 2012). Furthermore, a thematic network is presented that group the identified research themes, establishing a reference framework for researchers and future research based on bibliometric networks (Batagelj \& Cerinšek, 2013).

Finally, this research is structured as follows. Section II deals with the methodology of the bibliometric study, including the dataset. Section III demonstrates the performance bibliometric analysis including the main authors, countries, publication, and organizations. Furthermore, this section presents the analysis of content of the SIC articles, in two ways: strategic diagrams and thematic network. Lastly, Section IV summarizes the main findings and conclusions.

\section{Methodology and Dataset}

\subsection{Methodology}

A specific methodology had been applied in order to evaluate the performance and conceptual structure of the journal, considering the most relevant publications and its impact. It also assesses its performance through the analysis of the main bibliometric indicators.

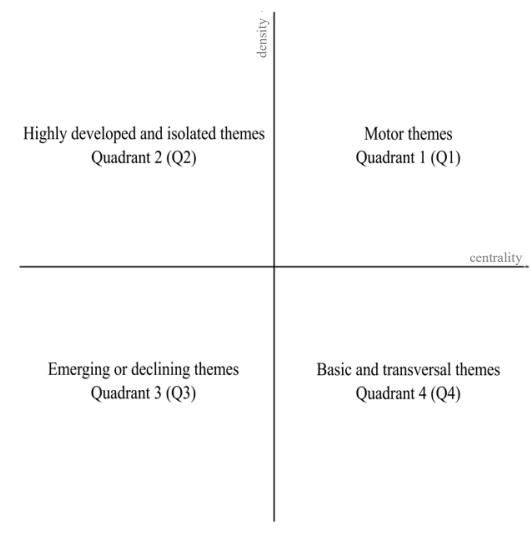

(a)
The methodology developed is composed by two parts: bibliometric performance analysis and thematic network. Firstly, performance analysis is based on bibliometric indicators which measure authors production and the impact achieved. Additionally, the most cited articles of the journal are identified using the H-Classics approach (Martínez et al., 2014), which is based on the h-index (Hirsch, 2005). Secondly, a thematic analysis based on a co-words network (Callon et al., 1991; Coulter et al., 1998) is developed using SciMAT (Cobo et al., 2012).

Taking into account the methodology developed by Cobo et al. (2011a), an analysis is carried out in three phases: (i) Research themes detection, (ii) Visualizing research themes and thematic network and (iii) Performance analysis. The research themes detected are visualized based on their centrality and density rank values, using two specialized tools: the strategic diagram and thematic network (Fig. 1) (Batagelj \& Cerinšek, 2013; Cobo et al., 2011b; Moral-Muñoz et al., 2020). The first one is a two-dimensions map divided into four areas according to their relevance, where the themes are represented as a sphere and its volume is proportional to publications associated with the theme and the second one is a diagram where the components are represented and its relationship. The four areas according to their relevance are Motor themes (Q1: Upper-right quadrant), Highly developed and isolated themes (Q2: Upper-left quadrant), Emerging or declining themes (Q3: Lower-left quadrant), and Basic and transversal themes (Q4: Lower-right quadrant).

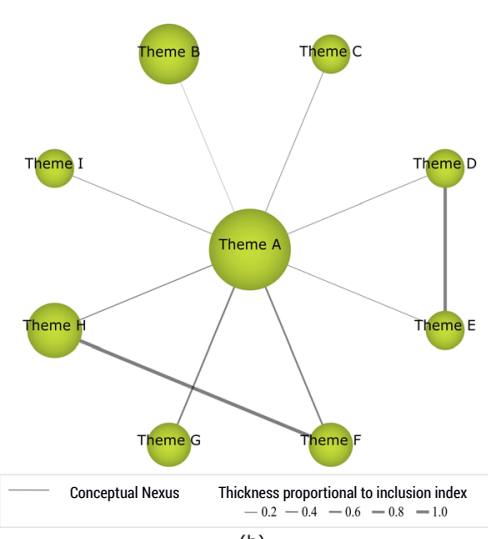

(b)

Figure 1. Structure of the (a) strategic diagram and (b) thematic network 


\subsection{Dataset}

To collect the raw data of Studies in Informatics and Control journal available on the Web of Science $(W o S)$ the following advance query was used: $I S=$ "1220-1766". Refined by: DOCUMENT TYPES $=($ ARTICLE OR REVIEW $)$ AND [excluding] PUBLICATION YEARS:(2020). This query retrieved a total of 531 publications (articles and reviews) from 2008 to 2019. Furthermore, citations of these publications were also analysed; they were counted up to 15 th February 2020.

The SIC publications were downloaded as plain text and imported into SciMAT software to build the knowledge base for science mapping analysis. Thus, the bibliographic information stored by WoS (affiliations, authors, references, date of publication, keywords and citations obtained, mainly) was saved for each publication, which allows to analyse the data, identify relationships and, consequently, obtain better results in the analysis of the science maps. In addition, in order to improve and guarantee the quality of the raw data, a revision process was applied. It analyses and merges the concepts that have the same meaning or represent the same concept (i.e. "ML-MACHINE-LEARNING", "MACHINE-LEARNING" and "MACHINELEARNING-(ML)" were grouped as "MACHINE-LEARNING").

As a next step, the SciMAT period manager was used to avoid data flatness. The best approach when analysing the evolution of the data is to evaluate them year by year, but sometimes it is advisable to group them in periods in order to generate a sufficient corpus of publications for analysis. In this case, the best option was to evaluate the all the years as a whole period.

\section{Bibliometric and Content Analysis}

This section evaluates the bibliometric performance of SIC journal in terms of publication, citations, and impact. The bibliometric performance analysis is structured into four parts: (i) whole production and impact of published documents; (ii) production of authors, countries and organizations and impact of authors; (iii) H-classic analysis; and (iv) analysis of content of the articles published.

\subsection{Publications and Citations}

Figure 2 shows the distribution of cites and SIC publications per year. Since the first year, three milestones in the development of the journal can be observed. The first milestone considers the first historical maximum in terms of annual publications after a period of growth of three consecutive years (2010). The second milestone is related to the minimum recorded in the last five years (2014) and the third corresponds to the historical maximum recorded by the journal (2016). Nevertheless, SIC publications show a pattern of growth that is expected to continue in the coming years despite the identified falls.

The citation distribution showed a positive developmental trend from 2008 to 2019. During this period, a total of 2.075 citations were recorded and its average citation per cited article was 3,91 according to the $W o S$.

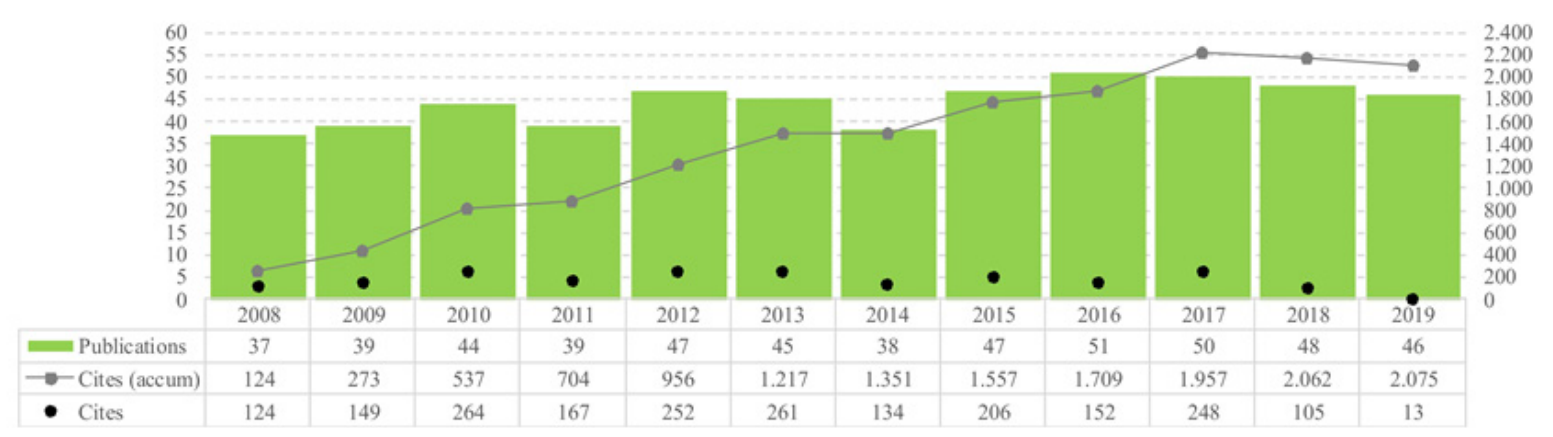

Figure 2. Distribution of publications and cites retrieved by year 


\subsection{Most Productive Authors, Countries and Organizations, and Most Cited Authors}

To understand the SIC evolution, it is also important to know which are the most productive and cited authors, along with the geographic distribution of publications and organizations.

Table 1 shows the most productive authors, countries and organizations, and most cited authors during the period 2008-2019. There was a tie in some positions between various authors, organizations or countries; thus, all of them have been included in an alphabetical order.

It is important to mention that only two of the most cited authors are not among the most productive authors: Antucheviciene, J. and Orchard, M.E. This situation reflects a coherence between the impact and productivity of the journal's authors.

In terms of internationalization, SIC journal has the participation of 60 countries from the 5 continents. Among the most productive countries, a balance can be observed between European, Asian and American countries, strengthening the international impact of the SIC journal.

This fact also coincides with the performance presented by the most productive organizations.
In terms of quantity and quality, the SIC journal is still growing and consolidating its position as a journal of reference in the IT field with emphasis on Advanced Control, Modelling and Optimization.

\subsection{Most Relevant Publications, Authors, Countries and Organizations}

The H-Classics method (Martínez et al., 2014), based on the well-known h-index (Hirsch, 2005) serves as an impartial criterion to systematize the identification of the classic papers of any research field. This method is used to discover the core paper in the SIC journal, and therefore, identify the authors, countries, and organizations that more have contributed (Figure 3).

The search query used in the database WoS has an h-index of 18 . Using as reference the h-index value, the core publications and its citations (including average per year) are presented in the Figure 3. Considering it, the main author are Zavadskas, E. K. (5), Tuba, M. (3), Turskis, Z. (3), Iqbal, J. (2), Orchard, M. (2) and Stanujkic, D. (2). In this way, the most productive and cited authors and the most relevant authors are consistent in both sections.

With regard to production by countries, Serbia (6), Lithuania (5) and Romania (3) are the most productive countries in terms of most relevant

Table 1. Most productive authors, countries, and organizations, and most cited authors

\begin{tabular}{|c|c|c|c|}
\hline (Publications) Author(s) & $\begin{array}{l}\text { (Cites) Author(s) } \\
\text { [without self citation] }\end{array}$ & $\begin{array}{l}\text { (Publications) } \\
\text { Country }\end{array}$ & (Publications) Organization(s) \\
\hline (14) Popescu, D. & (189) Zavadskas, E. K. & (213) Romania & $\begin{array}{l}\text { (47) National Institute for Research and } \\
\text { Development in Informatics ICI Bucharest }\end{array}$ \\
\hline (13) Benrejeb, M. & (145) Turskis, Z. & (47) France & (35) Politehnica University of Bucharest \\
\hline (12) Thorsteinsson, G. & (129) Tuba, M. & (40) Tunisia & (17) Pontificia Universidad Católica de Valparaíso \\
\hline (10) Borne, P.; Radulescu, Z. & (66) Balog, A. & (30) Chile & $\begin{array}{l}\text { (13) Lucian Blaga University of Sibiu; Vilnius } \\
\text { Gediminas Technical University }\end{array}$ \\
\hline (9) Balog, A. & (65) Thorsteinsson, G. & (25) India & (12) University of Oradea \\
\hline $\begin{array}{l}\text { (8) Alexandru, A.; } \\
\text { Zavadskas, E. K. }\end{array}$ & $\begin{array}{l}\text { (63) Niculescu, A.; } \\
\text { Pribeanu, C. }\end{array}$ & (19) South Korea & $\begin{array}{l}\text { (11) Bucharest University of Economic Studies; } \\
\text { Nanjing University of Science and Technology; } \\
\text { Petroleum-Gas University of Ploieşti }\end{array}$ \\
\hline $\begin{array}{l}\text { (6) Andrei, N.; Banciu, D.; } \\
\text { Cabrera, E.; Duta, L.; Filip, F.. G.; } \\
\text { Resteanu, C.; Susnea, I. }\end{array}$ & (56) Orchard, M. E. & (16) Mexico & $\begin{array}{l}\text { (8) Romanian Academy; University of Craiova; } \\
\text { Valahia University of Târgovişte }\end{array}$ \\
\hline $\begin{array}{l}\text { (5) Christov, N.; Czibula, I. G.; } \\
\text { Kou, G.; Popescu, C.; Popescu, N.; } \\
\text { Turskis, Z. }\end{array}$ & (53) Bacanin, T.; Page, T. & (15) United Kingdom & $\begin{array}{l}\text { (7) Ecole Nationale d'Ingénieurs de Tunis; Spiru } \\
\text { Haret University; Technical University of Cluj- } \\
\text { Napoca; Universidad de Valparaíso }\end{array}$ \\
\hline
\end{tabular}




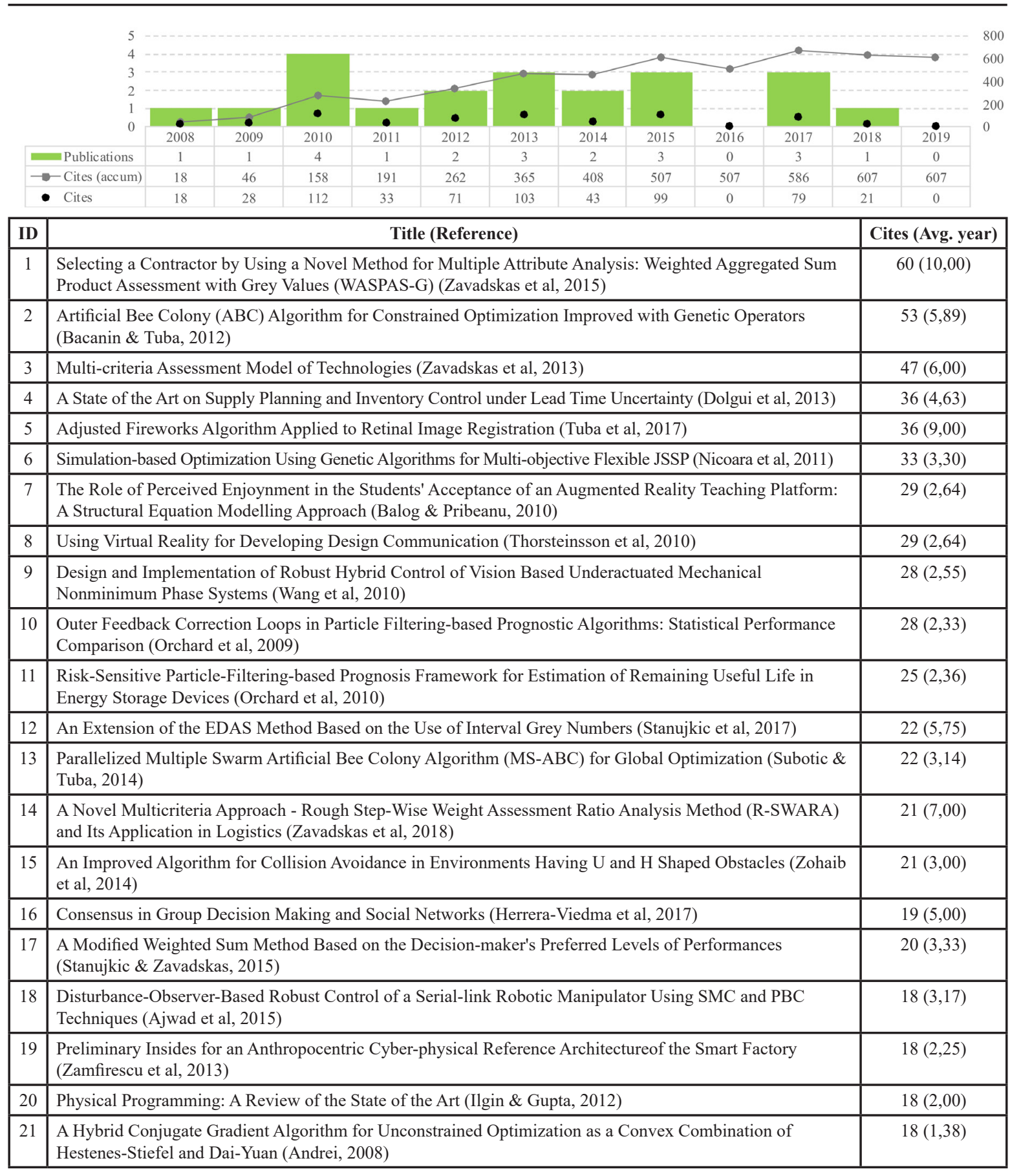

Figure 3. H-Classics of Studies in Informatics and Control (h-index=18)

publications. Finally, the most productive organizations identified in this section are Vilnius Gediminas Technical University (5), John Naisbitt University (4), Georgia Institute of Technology (2), National Institute for Research and Development in Informatics (2) and University of Chile (2).

\subsection{Analysis of Content of the Articles Published}

SIC journal research performance is presented below, identifying and visualizing the main themes from 2008 to 2019 using SciMAT. Figure 4 (a) presents the strategic diagram, including the number of publications that each theme concentrates, number of citations, h-index and average citations achieved by each one according to the results obtained from the query applied in $W o S$ and their thematic networks.

During the period 2008-2019, 12 research themes related to innovative research and practice in IT, integration of IT with control, IT use in control and management systems, application of IT in socio-economic systems and manufacturing 


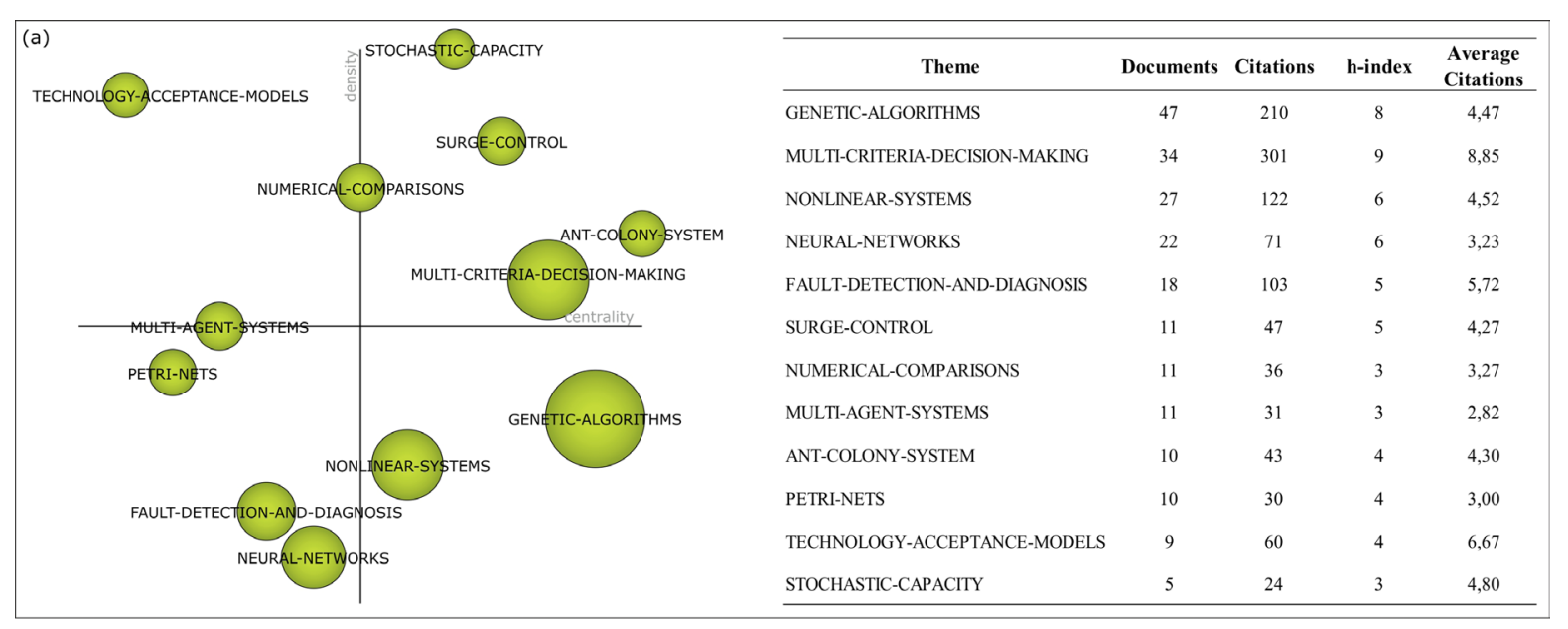
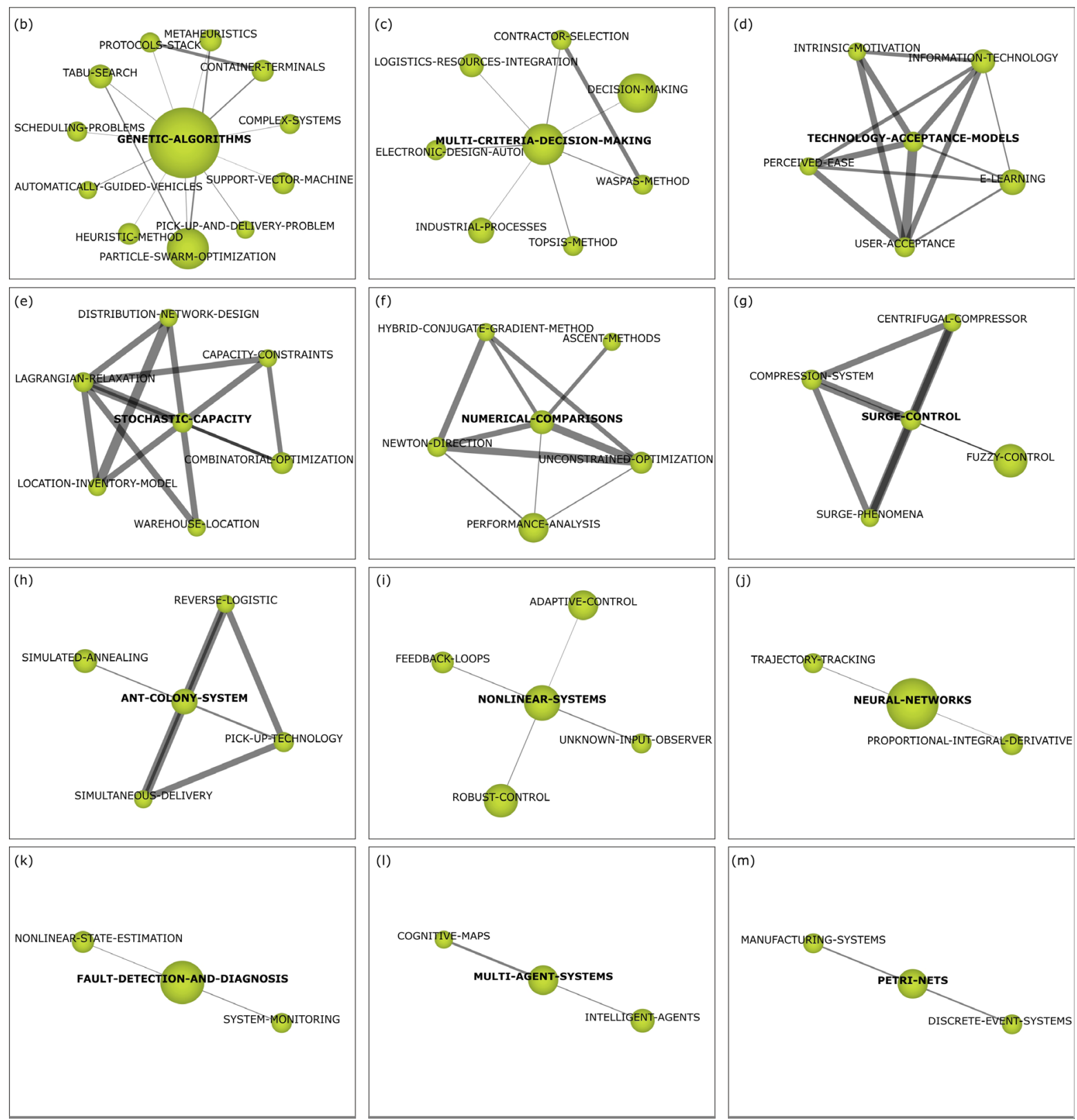

Figure 4. (a) Strategic diagram and performance from 2008 to 2019. Thematic network (b) GENETIC-

ALGORITHMS, (c) MULTI-CRITERIA-DECISION-MAKING, (d) TECHNOLOGY-ACCEPTANCEMODELS, (e) STOCHASTIC-CAPACITY, (f) NUMERICAL-COMPARISONS, (g) SURGE-CONTROL,

(h) ANT-COLONY-SYSTEM, (i) NONLINEAR-SYSTEMS, (j) NEURAL-NETWORKS, (k) FAULTDETECTION-AND-DIAGNOSIS, (l) MULTI-AGENT-SYSTEMS and (m) PETRI-NETS. 
processes, as displayed in the strategic diagram: GENETIC-ALGORITHMS (Fig 4.b), MULTICRITERIA-DECISION-MAKING (Fig 4.c), TECHNOLOGY-ACCEPTANCE-MODELS (Fig 4.d), STOCHASTIC-CAPACITY (Fig 4.e), NUMERICAL-COMPARAISONS (Fig 4.f), SURGE-CONTROL (Fig 4.g), ANT-COLONYSYSTEM (Fig 4.h), NONLINEAR-SYSTEMS (Fig 4.i), NEURAL-NETWORKS (Fig 4.j), FAULT-DETECTION-AND-DIAGNOSIS (Fig 4.k), MULTI-AGENT-SYSTEMS (Fig 4.1) and PETRI-NETS (Fig 4.m).

In this way, seven research themes are considered core because of their contribution to the growth of the field and journal (Motor themes and Basic and transversal themes): GENETICALGORITHMS, NONLINEAR-SYSTEMS, MULTI-CRITERIA-DECISION-MAKING, NUMERICAL-COMPARISONS, ANTCOLONY-SYSTEMS, SURGE-CONTROL and STOCHASTIC-CAPACITY.

The performance measures of the main themes presented in Figure 4.a show the number of documents, citations, average citations and h-index per theme. In this way, the most productive themes (more than 15 documents) are included in the Basic and transversal themes (GENETIC-ALGORITHMS (47) and NONLINEAR-SYSTEMS (27)), Motor themes (MULTI-CRITERIA-DECISION-MAKING (34)) and Emerging or declining themes (NEURALNETWORKS (22) and FAULT-DETECTIONAND-DIAGNOSIS (18)).

In the same way, the most cited themes (more than 70 cites) are included in the Basic and transversal themes (GENETIC-ALGORITHMS (210) and NONLINEAR-SYSTEMS (122)), Motor themes (MULTI-CRITERIA-DECISION-MAKING (301)) and Emerging or declining themes (NEURAL-NETWORKS (71) and FAULTDETECTION-AND-DIAGNOSIS (103)).

On the other hand, the thematic networks of each theme are shown in Figure 4 and analysed below.

In terms of productivity, the most productive theme of the SIC journal is GENETICALGORITHMS (Figure 4.b), which is related mainly with COMPLEX-SYSTEMS,
SUPPOR-VECTOR-MACHINE, PARTICLESWARM-OPTIMIZATION, HEURISTICMETHOD, AUTOMATICALLY-GUIDEDVEHICLES, SCHEDULING-PROBLEMS, TABU-SEARCH, PROTOCOLS-STACK, METHAHEURISTICS and CONTAINERTERMINALS. Taking into account that this theme is allocated in the Quadrant 4, its role is transversal for the rest of themes.

In a similar case, NONLINEAR-SYSTEMS is allocated in the Quadrant 4, where its role is transversal for the rest of themes. The theme NONLINEAR-SYSTEMS (Figure 4.e) is mainly related to themes such as ADAPTIVE-CONTROL, FEEDBACK-LOOPS, ROBUST-CONTROL and UNKONWN-INPUT-OBSERVER.

The theme MULTI-CRITERIA-DECISIONMAKING (Figure 4.c) is the second ranked in terms of productivity and the first in citations achieved. It is mainly related to themes such as DECISIONMAKING, WASPAS-METHOD, TOPSISMETHOD, INDUSTRIAL-PROCESSES, ELECTRONIC-DESIGN-AUTOMOTION, LOGISTICS-RESOURCES-INTEGRATION and CONTRACTOR-SELECTION. It is allocated in the Quadrant 1 and its role is motor for the rest of themes.

NEURAL-NETWORKS and FAULTDETECTION-AND-DIAGNOSIS are allocated in the Quadrant 3, where their role are emerging themes. The theme NEURALNETWORKS (Figure 4.j) is fourth ranked in terms of productivity and fifth in citations achieved. It is mainly related to themes such as PROPORTIONAL-INTEGRAL-DERIVATE and TRAJECTORY-TRACKING. In this way, FAULTDETECTION-AND-DIAGNOSIS (Figure 4.k) is fifth ranked in terms of productivity and fourth in citations achieved. It is mainly related to themes such as NONLINEAR-STATE-ESTIMATION and SYSTEM-MONITORING.

Finally, according to the results obtained and taking into account the main research themes related to the most cited themes, it could be possible to state that the publications and research themes covered by the Studies in Informatics and Control journal are linked, strong and synergies between them. 


\section{Conclusion}

The evolution of Studies in Informatics and Control journal is positive since its beginning to nowadays. Moreover, given the large volume of publications and citations received, as well as the research themes identified and their evolution in the main databases, it is expected that the scientific community interest for the journal continues or even keeps growing over the coming years.

In the bibliometric performance analysis, SIC journal presents papers coauthorized by 1.112 researchers from 462 organizations and 60 different countries during the period 20082019. A number of 531 publications with 2.075 citations are published in SIC journal according to Web of Science Core Collection. The most productive authors are Popescu, D., Benrejeb, M., Thorsteinsson, G., Niculescu, A., Page, T., Tian, Y., Wang, H. P., Borne, P., Radulescu, C. Z., Balog, A., Alexandru, A., Zavadskas, E. K., Pribeanu, C., Radulescu, M., Tuba, M., Andrei, N., Banciu, D., Cabrera, E., Duta, L., Filip, F. G., Resteanu, C., Susnea, I., Christov, N., Czibula, I. G., Kou, G., Popescu, C., Popescu, N. and Turskis Z, and the most cited are Zavadskas, E. K., Turskis, Z., Tuba, M., Antucheviciene, J., Wang, H. P., Balog, A., Thorsteinsson, G., Niculescu, A., Pribeanu, C., Filip, F. G., Orchard, M. E., Bacanin, $\mathrm{N}$. and Page, T. The correspondence between the most productive and most cited authors reflects the balance and quality of the publications included within the journal.

In such a way, the most productive organizations are National Institute for Research and Development in Informatics ICI Bucharest, Politehnica University of Bucharest, Pontificia Universidad Católica de Valparaíso, L'École centrale de Lille, Lucian Blaga University of Sibiu, Vilnius Gediminas Technical University, University of Oradea, Bucharest University of Economic Studies, Nanjing University of Science and Technology, Petroleum-Gas University of Ploiești, University of Iceland, University of Loughborough, Romanian Academy, University of Craiova, Valahia University of Targoviste, Ecole Nationale d'Ingénieurs de Tunis, Spiru Haret University, Technical University of Cluj-Napoca and Universidad de Valparaiso.

Regarding to relevant bibliometric indexes, the SIC journal presents an h-index of 18 , an indicator that reflects the number of reference publications for their impact on its development. This group of publications concentrate 553 citations and present an average of 30,72 citations each. The authors with more than one publication within the most cited are Zavadskas, E. K., Tuba, M., Turskis, Z., Iqbal, J., Orchard, M. and Stanujkic, D. With regard to the organizations with the most relevant publications, the Vilnius Gediminas Technical University has 5 publications, the John Naisbitt University has 4 publications and the Georgia Institute of Technology, National Institute for Research and Development in Informatics, and University of Chile have 2 publications each. This coincides with the results obtained initially, which reflects a coherence between productivity and the impact of authors and organizations.

According to the conceptual analysis developed using SciMAT tool, two main research themes groups are identified. The first group is the themes considered as core for their contribution to the growth of the field and journal (Motor themes and Basic and transversal themes): GENETIC-ALGORITHMS, NONLINEARSYSTEMS, MULTI-CRITERIA-DECISIONMAKING, NUMERICAL-COMPARISONS, ANT-COLONY-SYSTEMS, SURGE-CONTROL and STOCHASTIC-CAPACITY, and the second one that is related to parallel and emerging themes: NEURAL-NETWORKS, FAULTDETECTION-AND-DIAGNOSIS, PETRI-NETS, MULTI-AGENT-SYSTEMS and TECHOLOGY ACCEPTANCE-MODELS.

On analysing these themes and their relationship, the research finds that the development of SIC journal will mainly support the following areas: Artificial Intelligence and Machine Learning, Security, Automatic Control, System Modelling and Optimization as well as new IT\&C infrastructure management used in socioeconomic systems and industrial processes.

Finally, it is important to note that this analysis allows the identification of common themes that can be used to achieve the research lines related to the purpose and objectives of Studies in Informatics and Control journal.

\section{Acknowledgements}

The authors want to thank the support of FEDER funds (TIN2016-75850-R), CONACYT Consejo Nacional de Ciencia y Tecnología and DGRI Dirección General de Relaciones Internacionales. 


\section{REFERENCES}

Batagelj, V. \& Cerinšek, M. (2013). On bibliographic networks, Scientometrics, 96(3), 845-864.

Börner, K., Theriault, T. N. \& Boyack, K. W. (2015). Mapping science introduction: past, present and future, Bulletin of the Association for Information Science and Technology, 41(2), 12-16.

Callon, M., Courtial, J. P. \& Laville, F. (1991). Coword analysis as a tool for describing the network of interactions between basic and technological research: The case of polymer chemsitry, Scientometrics, 22(1), 155-205.

Cobo, M. J., López-Herrera, A. G., Herrera-Viedma, E. \& Herrera, F. (2011a). An approach for detecting, quantifying, and visualizing the evolution of a research field: A practical application to the Fuzzy Sets Theory field, Journal of Informetrics, 5(1), 146-166.

Cobo, M. J., López-Herrera, A. G., Herrera-Viedma, E. \& Herrera, F. (2011b). Science mapping software tools: Review, analysis, and cooperative study among tools, Journal of the American Society for Information Science and Technology, 62(7), 1382-1402.

Cobo, M. J., López-Herrera, A. G., Herrera-Viedma, E. \& Herrera, F. (2012). SciMAT: A new science mapping analysis software tool, Journal of the American Society for Information Science and Technology, 63(8), 1609-1630.

Coulter, N., Monarch, I. \& Konda, S. (1998). Software engineering as seen through its research literature: A study in co-word analysis, Journal of the American Society for Information Science, 49(13), 1206-1223.

Garcia-Garcia, L. A. \& Rodriguez-Salvador, M. (2018). Uncovering 3D bioprinting research trends: A keyword network mapping analysis, International Journal of Bioprinting, 4(2). DOI: 10.18063/ijb. v4i2.147

Gaviria-Marin, M., Merigó, J. M. \& BaierFuentes, H. (2019). Knowledge management: A global examination based on bibliometric analysis, Technological Forecasting and Social Change, 140, 194-220.

Glänzel, W. (1996). The need for standards in bibliometric research and technology, Scientometrics, 35(2), 167-176.

Gorraiz, J. \& Schloegl, C. (2008). A bibliometric analysis of pharmacology and pharmacy journals: Scopus versus Web of Science, Journal of Information Science, 34(5), 715-725.

Gutiérrez-Salcedo, M., Martínez, M. A., MoralMunoz, J. A., Herrera-Viedma, E. \& Cobo, M. J. (2018). Some bibliometric procedures for analyzing and evaluating research fields, Applied Intelligence, $48(5), 1275-1287$.

Hirsch, J. E. (2005). An index to quantify an individual's scientific research output. In Proceedings of the National academy of Sciences, 102(46), (pp. 16569-16572).

Kiesslich, T., Weineck, S. B. \& Koelblinger, D. (2016). Reasons for journal impact factor changes: influence of changing source items, PloS One, 11(4). DOI: 10.1371/journal.pone.0154199

Li, Y., Xu, Z., Wang, X. \& Filip, F. G. (2019). Studies in Informatics and Control: A Bibliometric Analysis from 2008 to 2019, International Journal of Computers, Communications \& Control, 14(6), 633-652.

López-Robles, J. R., Guallar, J., Gamboa-Rosales, N. K., Otegi-Olaso, J. R. \& Cobo, M. J. (2019a). Mapa de la estructura intelectual de El profesional de la información de 2014 a 2018, Hipertext. net, 19, 115125. DOI: 10.31009/hipertext.net.2019.i19.09

López-Robles, J. R., Guallar, J., Otegi-Olaso, J. R. \& Gamboa-Rosales, N. K. (2019b). El profesional de la información (EPI): Bibliometric and thematic analysis (2006-2017), El Profesional de la Información, 28(4), e280417. DOI: 10.3145/epi.2019.jul.17

López-Robles, J. R., Otegi-Olaso, J. R., Arcos, R., Gamboa-Rosales, N. K. \& Gamboa-Rosales, H. (2018). Mapping the structure and evolution of JISIB: A bibliometric analysis of articles published in the Journal of Intelligence Studies in Business between 2011 and 2017, Journal of Intelligence Studies in Business, 8(3), 9-21.

López-Robles, J. R., Otegi-Olaso, J. R., Porto-Gómez, I. \& Cobo, M. J. (2019c). 30 years of intelligence models in management and business: A bibliometric review, International Journal of Information Management, 48, 22-38.

López-Robles, J. R., Otegi-Olaso, J. R., Porto-Gómez, I., Gamboa-Rosales, H. \& Gamboa-Rosales, N. K. (2019d). Understanding the intellectual structure and evolution of Competitive Intelligence: a bibliometric analysis from 1984 to 2017, Technology Analysis \& Strategic Management, 1-16. DOI: 10.1080/09537325.2019.1686136

Martínez, M. A., Herrera, M., López-Gijón, J. \& Herrera-Viedma, E. (2014). H-Classics: Characterizing the concept of citation classics through H-index, Scientometrics, 98(3), 1971-1983.

Moral-Muñoz, J. A., Carballo-Costa, L., HerreraViedma, E. \& Cobo, M. J. (2019). Production trends, collaboration, and main topics of the integrative 
and complementary oncology research area: A bibliometric analysis, Integrative Cancer Therapies, 18. DOI: $10.1177 / 1534735419846401$.

Moral-Muñoz, J. A., Herrera-Viedma, E., SantistebanEspejo, A. \& Cobo, M. J. (2020). Software tools for conducting bibliometric analysis in science: An up-todate review, El Profesional de la Información, 29(1). e290103. DOI: 10.3145/epi.2020.ene.03

Murgado-Armenteros, E. M., Gutiérrez-Salcedo, M., Torres-Ruiz, F. J. \& Cobo, M. J. (2015). Analysing the conceptual evolution of qualitative marketing research through science mapping analysis, Scientometrics, 102(1), 519-557.

Petersen, J., Hattke, F. \& Vogel, R. (2017). Editorial governance and journal impact: a study of management and business journals, Scientometrics, $112(3), 1593-1614$
Schneider, J. W. (2005). Verification of bibliometric methods' applicability for thesaurus construction, ACM SIGIR Forum, 39(1), 63-64. ACM New York, NY, USA.

Stek, P. E. \& van Geenhuizen, M. S. (2016). The influence of international research interaction on national innovation performance: A bibliometric approach, Technological Forecasting and Social Change, 110, 61-70.

Wang, X., Xu, Z. \& Dzitac, I. (2019). Bibliometric Analysis on Research Trends of International Journal of Computers Communications \& Control, International Journal of Computers, Communications \& Control, 14(5), 711-732. 